\title{
CAD-Based Modeling Using Three Dimensional Point Cloud Data
}

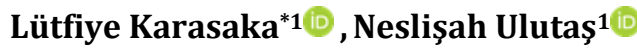

${ }^{1}$ Konya Technical University, Faculty of Engineering, Department of Geomatics Engineering, Konya, Turkey

Keywords
LiDAR
Terrestrial Laser Scanning
Point Cloud
Documentation
3D CAD Modeling

\section{INTRODUCTION}

Our country has an extremely rich and important cultural potential that contains numerous historical and cultural artifacts (Ministry of Culture and Tourism, 2021). Although today's modern buildings are designed to withstand various events, historical structures have suffered many natural or human-induced damages until today. Architectural documentation studies for the transfer of these precious historical artifacts from the past to the present have proven to be an effective and useful method for the reconstruction and preservation of the building (Kushwaha et al., 2020). Nowadays, different perspectives have been obtained in architectural documentation applications thanks to the increasing developments in measurement technologies and the integration of photogrammetry into architectural applications. Terrestrial laser scanning method has become a more effective and current method compared to traditional measurement methods for architectural documentation studies. Terrestrial laser scanning technique is basically evaluated within the LIDAR (Light Detection and Ranging) system (Yakar et al., 2020). LIDAR technology is the name given to a remote sensing technology, commonly known as laser scanning technology, referred to as beam capture and distance determination (Sevgen, 2018). TLS is a non-destructive technique, and in recent years, has experienced great advances, which has resulted in important development in the field of graphic and metric documentation of objects in which no direct contact is involved. The advantage of using remote sensing technique is that it doesn't need any physical contact with the surface. Remotely accessed data are very important in case of cultural heritage site (Kushwaha et al., 2020; González et al. 2010). TLS is a method based on obtaining the XYZ coordinates of many points as a result of sending laser pulses to the target object and measuring the distance between the device and the target. A point cloud is represented as a function of the intensity of the reflected laser beam (Gumilar et al., 2020; Uzun \& Spor, 2019). 
Using 3D point cloud data obtained by laser scanning method, the following studies can be performed through CAD applications: basic measurement data, orthophoto image extraction, 2D or 3D drawings, solid surface models, 3D animations, texture covered 3D model extraction. It is seen that high resolution 3D point cloud data is used in architectural survey studies, in the production of orthophoto to ready for CAD drawing (Hassan \& Fritsch, 2019; Lin et al., 2019; Bonfanti et al., 2013). In this study, 3D CAD drawings of Ali Efendi Muallimhane, one of the historical and cultural works of Konya province, were created from high resolution 3D point cloud data and their orthophotos.

\section{METHOD}

\subsection{Terrestrial Laser Scanner Method}

Terrestrial laser scanning technology is a method that samples or scans objects directly, precisely and automatically obtaining 3D coordinates $(\mathrm{x}, \mathrm{y}, \mathrm{z})$ with the help of LiDAR technology (Beg, 2018; Bonfanti et al., 2013). It is based on a system that scans the target object in series of points within limited angles in horizontal and vertical directions and enables it to be displayed as point clouds (Lichti \& Gordon, 2004). The location of a point is determined by the time it takes for the LiDAR signal to hit the target and the beam reflected from the target back to the scanner (Equation1). Scanner centered polar coordinates are obtained as a result of these operations. These polar coordinates are converted into cartesian coordinates (Figure1).

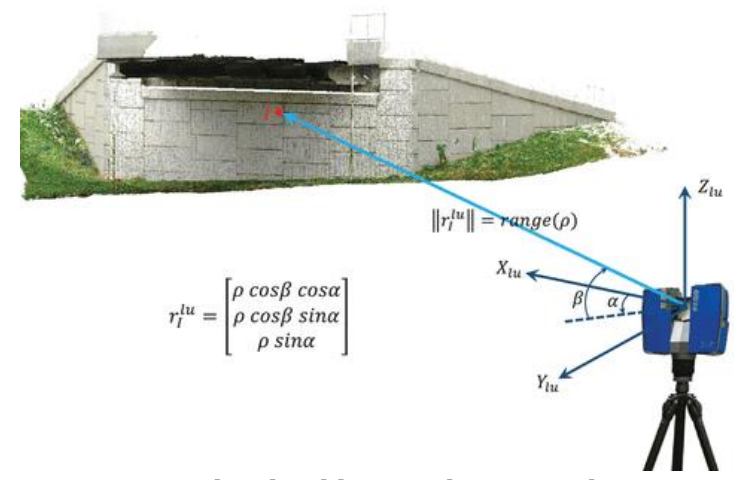

Figure 1. A typical pulsed laser telemeter, the operating principle (Lin et al. 2019).

$$
\Delta R=\mathrm{c} \frac{\Delta t}{2}
$$

\section{$R$ : the distance between point $A$ and point $B$ $c$ : the velocity of electromagnetic radiation $r$ : measured time interval}

As a result, the point cloud formed by millions of points is obtained. A point cloud is the sum of $\mathrm{XYZ}$ coordinates that enable understanding of the spatial distribution of an object or a region within a general reference system. These point clouds contain different resolutions, sampling densities and attributes as well as different scenes and objects (Kushwaha et al., 2020; Beg 2018; Altuntaş \& Yıldız, 2008).
In this study, data acquisition was carried out with the help of Terrestrial Laser Scanner (TLS) FaroFocus 3DX 330. This laser scanner is suitable for 3D documentation and land surveys. It can produce detailed 3D images of complex structures in a few minutes. Focus $3 \mathrm{D}$, based on phase shift measurement method. This type of scanner uses a continuous wave laser as the carrier for a modulated signal (Figure 2). The phases of the emitted and received signals are compared. Scanners of this type have a lower range, higher measurement speeds and better precision than scanners based on the principle of time of flight. Since this method has a comprehensive signaling structure, it offers more accurate and precise results compared to laser scanners working with other methods (Karasaka \& Beg, 2021: González et al., 2010). The relation between phase difference and range is (Equation2):

$$
D=\frac{c \cdot \theta}{4 \pi f}
$$

$$
\begin{aligned}
& \text { D: Distance between laser scanner and object } \\
& \text { c: Speed of light } \\
& \Theta: \text { Phase difference } \\
& \text { f: Frequency }
\end{aligned}
$$

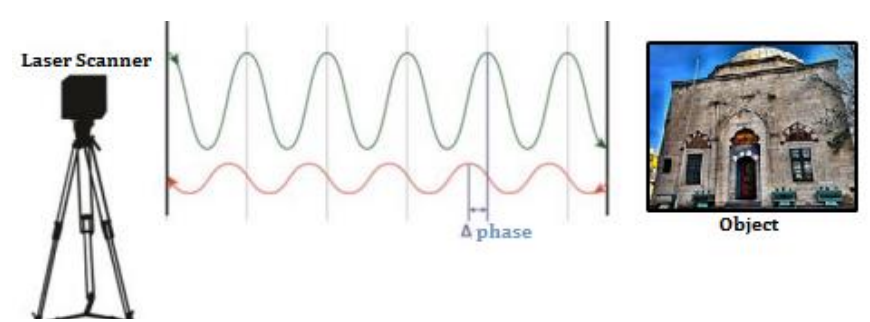

Figure 2. The working principle of Phase shift measurement

\subsection{Usability of Terrestrial Laser Scanners in Architectural Documentation Studies}

High resolution 3D point cloud data is frequently used in documentation studies of historical and cultural heritage such as survey, restitution and restoration (Wojtkowska et al., 2021). In the documentation process of a building, terrestrial laser scanners are frequently preferred in architectural facade scans because they provide an accuracy of $\mathrm{mm}$ level. Thanks to this point cloud data representing the structure, 3D coordinate data of objects or structures that are difficult to survey can be obtained (Okuyucu \& Çoban, 2019; Kersten et al., 2009; Hassan \& Fritsch, 2019). Architectural documentation studies are carried out within certain standards. The survey work to be carried out with 3D point cloud data of any object or area to be recorded shows the feature of base data for restitution and restoration works to be carried out in the future. Using this data, the 3D model of the object or structure to be scanned can be recorded and stored. When compared with traditional measurement methods, it is seen that models created with point cloud data make accurate measurements at a rate of $99.9 \%$. Thanks to this method, in which the most complex geometries of the structures are revealed exactly, the process-result relationship in architectural documentation processes works extremely quickly (Uzun \& Spor, 2019). 
With the transfer of the obtained point cloud data of the object or structures to the CAD program, the preparation of floor plans and section drawings and technical drawing operations can be performed. Thanks to the high quality orthophotos obtained from the point cloud data, 2D technical drawings can be made in architectural survey studies. In this way, the details of the object or the building can be shown on the 3D point cloud data and the current state of the building can be completed in the form of architectural survey work. Restitution studies can be prepared for problematic sections by integrating with previously obtained photographs and data obtained during the survey on the works that have been destroyed or structurally damaged (Uzun \& Spor, 2019).

Today, there are many software (AutoCAD, Sketchup, etc.) that offer the opportunity to work on point cloud. For example, AutoCAD software provides certain improvements and enhancements when working over the point cloud. With the point cloud plugin, using clipping tools, an existing area on the cloud can be focused and drawings can be made on the cropped area with the help of points. The cropped area includes any objects left within this area, along with the crop border. In addition, since these clipped areas now show a crosssection feature, they allow object creation with using point clouds depending on the density of the cloud. Another drawing method is to correctly identify the dynamic user-defined coordinate system on the target surface to be drawn (Prota Altar, 2020).

\subsection{Study Area}

The determined working site called "Ali Efendi Muallimhanesi" is located opposite to the northern entrance of Şerafettin Mosque in Karatay District of Konya Province. The 'Muallimhane', which was built by Hacl Ali in the early 15th century, was initially named 'Daru'l Kurra', and depending on the need, the school and 'Daru'l Huffaz'sections were opened and turned into an educational institution that includes levels that complement each other. It was closed at the end of the 19th century and was opened as Ali Efendi Madrasa instead. Before the Republic period it was used as a health museum and then as a mufti office. After 1968, it was transformed into a Children's Library under the Ministry of Culture, and after 1993 it was used as Ali Efendi Public Library. The library was evacuated in 2000 for repairs, and when the repairs were completed, it was allocated to the Konya Provincial Directorate in 2001. It was allocated to Konya Provincial Mufti in February 2015 by Konya Governorship for use in Quran and Islamic Related Services (Konya Metropolitan Municipality, 2021).

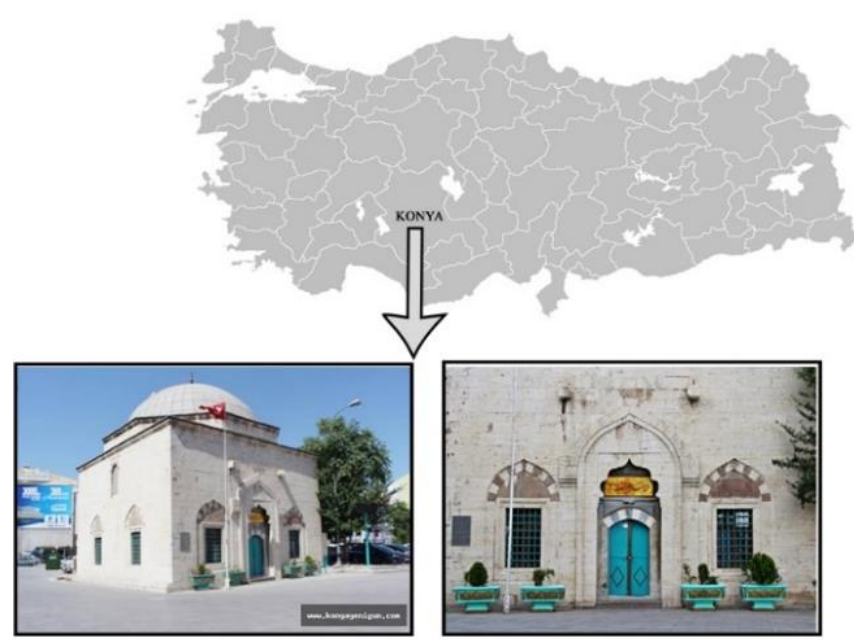

Figure 3. Study area, "Ali Efendi Muallimhanesi”, Konya

\section{APPLICATION}

Point cloud preprocedure consists of scan registration, alignment, noise cancellation, scaling and segmentation. These steps can be performed in TLS native software. Architectural survey with terrestrial laser scanning method workflow in general is definition as below (Moyano et al., 2021):

\section{i. Planning survey \\ ii. Detecting the angle and location of the scanner \\ iii. Scanning and acquiring point cloud data \\ iv. Processing of data in computer software \\ v. Transferring data to CAD environment \\ vi. Drawing plans, sections and views of the building in CAD environment}

In this study, Faro Laser Scanner X-330 Hdr was used. It is capable of scanning objects up to 330 meters away in direct sunlight with $0.2 \mathrm{~mm}$ accuracy, and objects up to 330 meters away with deviations between 3 and $5 \mathrm{~cm}$. It enables us to obtain colored point cloud data by integrating the photos taken at 360 degrees into the point cloud on the scanned data with 170 megapixel camera resolution. The scanner can produce point cloud data by generating 976,000 points per second (Table1). In this study, Scene Faro was used for the acquisition and processing of data. With Scene software, users can create stunning 3D visualizations of real world objects and environments and export that data in various formats (Faro, 2020).

Table 1. Features device of FaroFocus 3D X 330 (Faro 2020)

\begin{tabular}{cc}
\hline Scan Distance & $0.6-330 \mathrm{~m}$ \\
Size & $240 \times 200 \times 100 \mathrm{~mm}$ \\
Weight & $5,2 \mathrm{~kg}$ \\
Measuring Speed & 976,000 points / second \\
Accuracy & $\pm 2 \mathrm{~mm}$ \\
Camera & 70 megapixels \\
Resolution & $1 / 1,1 / 2,1 / 4,1 / 5,1 / 8,1 / 10,1 / 16,1 / 20,1 / 32$ \\
\hline
\end{tabular}


Scanning operations of the target object were carried out from the station points determined in such a way that one or more facade of the target can be seen and from the appropriate distance. The process of combining the scan data and creating the point cloud cluster for the target object has been completed in the faro scene software (Figure 4). From this stage on, the survey drawings of the façades of the building were made by taking 2D orthophotos obtained from the point cloud data (Figure 8). In addition, a drawing has been made illustrating the details of the building that has been made through points with the help of point cloud (Figure 6; Figure 7). There are a lot of plug-in for CAD softwares to processing and drawing of point clouds.

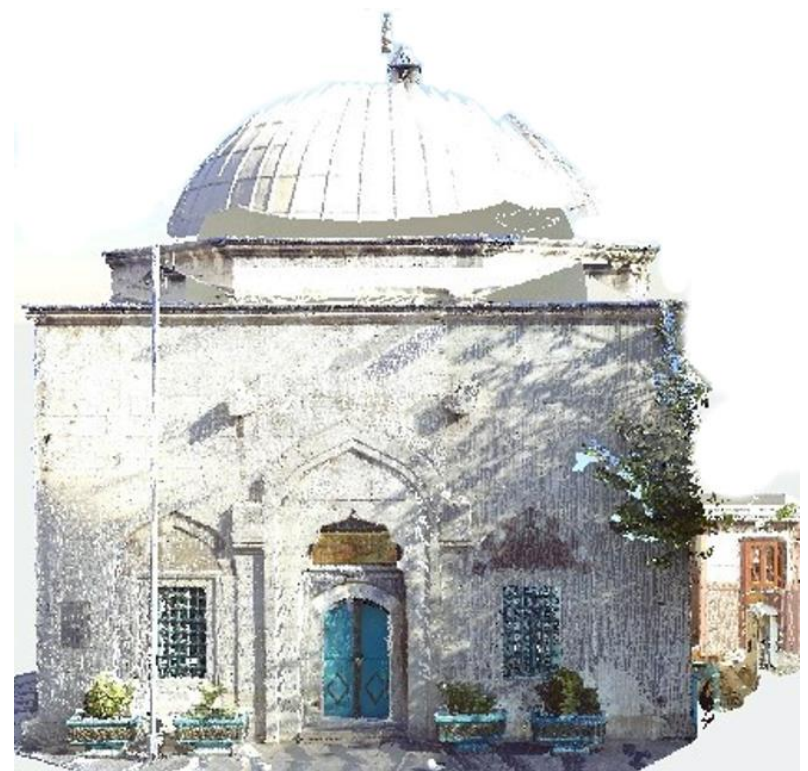

Figure 4: Point cloud data of Ali Efendi Muallimhanesi

Mesh model is generated in SCENE software via point cloud data (Figure 5).

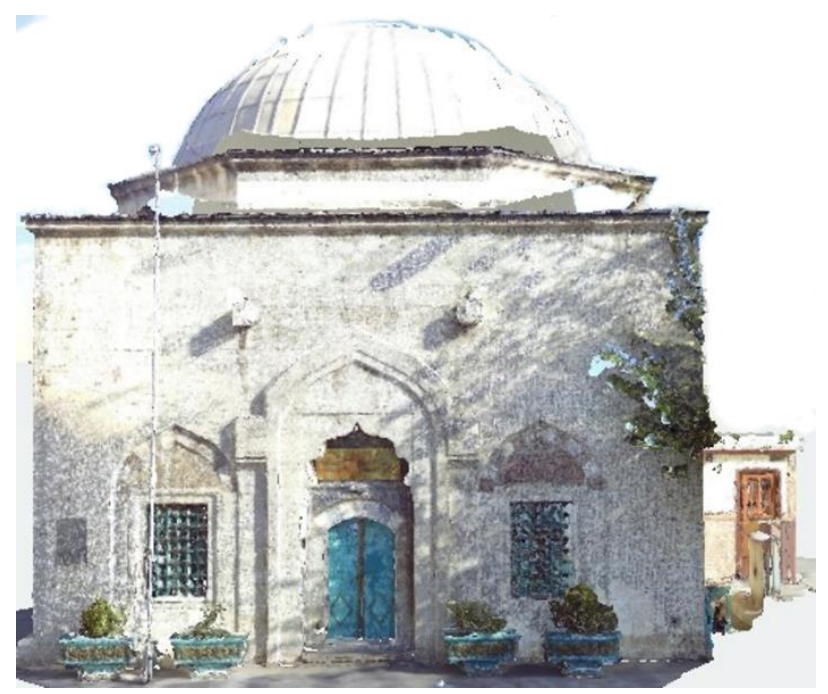

Figure 5: Mesh Model data of Ali Efendi Muallimhanesi

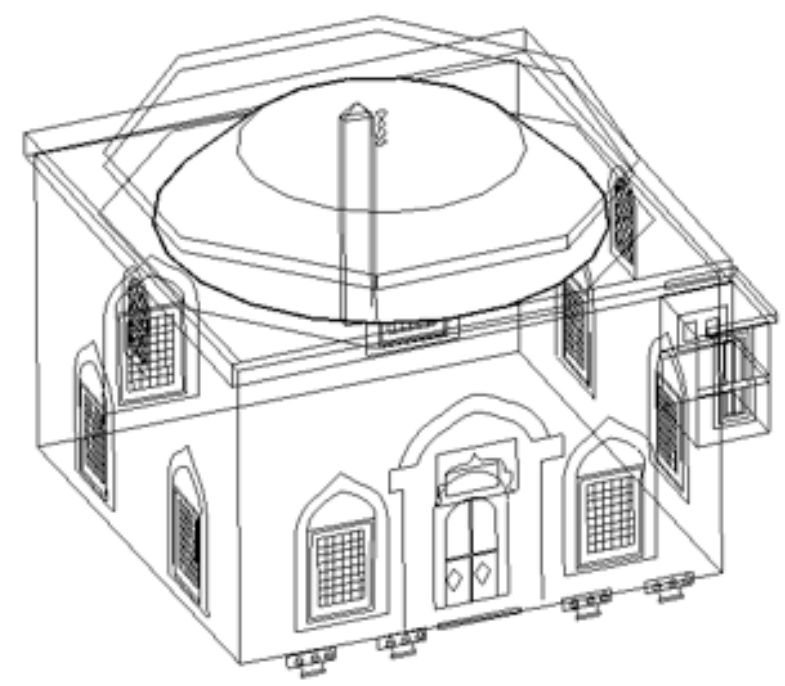

Figure 6. Drawing made by using Point Cloud

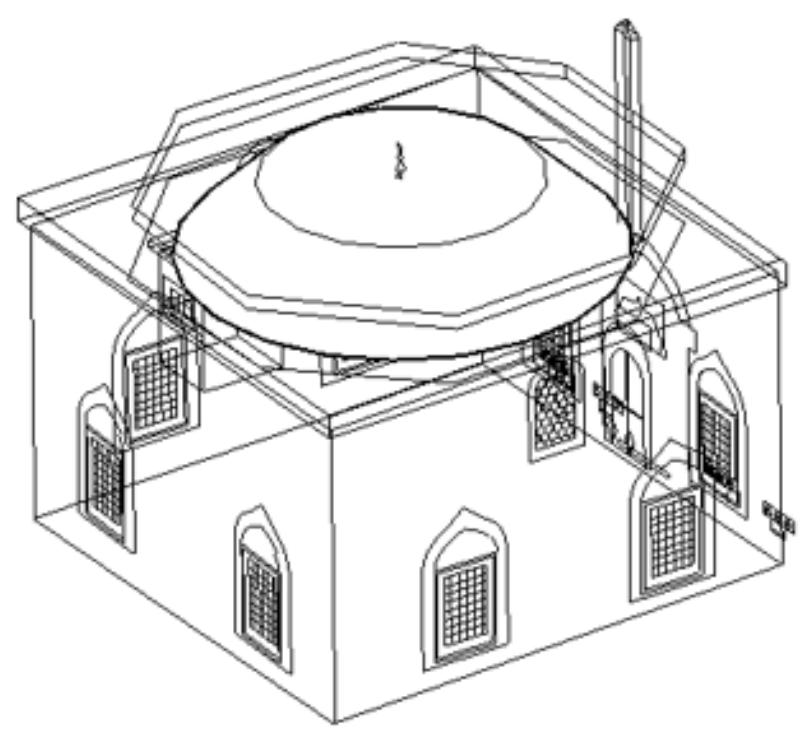

Figure 7. Drawing made by using Point Cloud

However, in accordance with the standards accepted in the survey studies, it is not possible to show the details of the building exactly in the drawings to be obtained by this method. This is due to the fact that points in a frequent and complex arrangement do not allow the drawing of the details of the building. In order to make 2D drawings for use in survey studies, orthophotos are produced over the desired sections from the point cloud data. In this way, 3D data is reduced to 2D data in the most accurate way. By means of orthophotos obtained, 2D or 3D technical drawings, 3D models in the form of solid surfaces and animations can be obtained. 

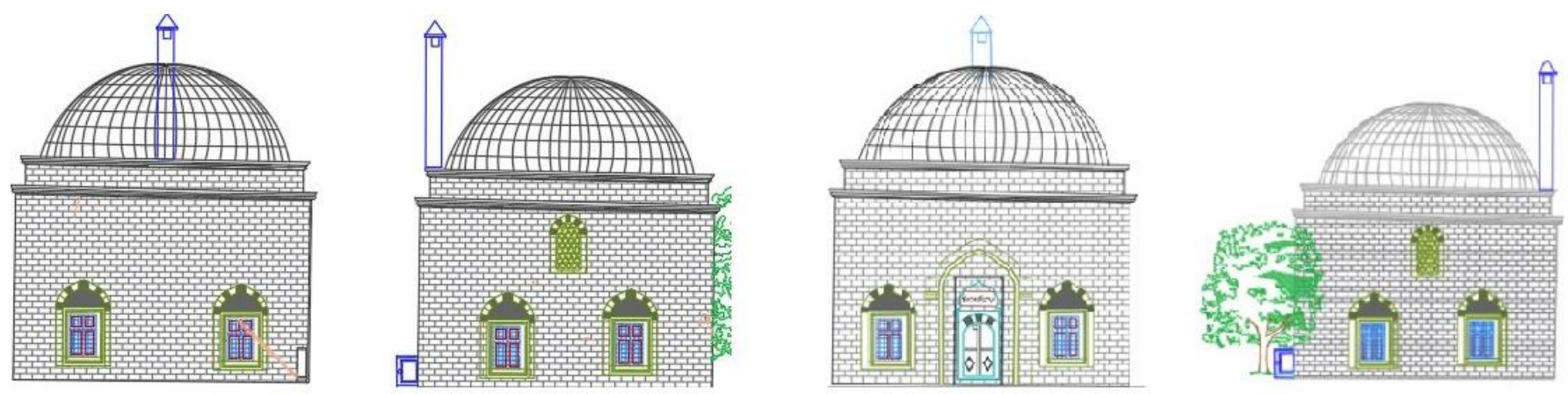

Figure 8. Architectural drawings of building facades made by using orthophoto

In addition, floor plans and section drawings of the whole building can be obtained easily (Figure 10). Precise thickness of the wall and all the dimensions can be obtained with the help of point cloud through laser scanner (Kushwaha et al., 2020). In this sudy, All the drawings that were extracted were of $\mathrm{mm}$ accuracy. In this study, meaningful drawings have been created in which the details of the object can be reflected more easily as a result of the drawing made using orthophotos.

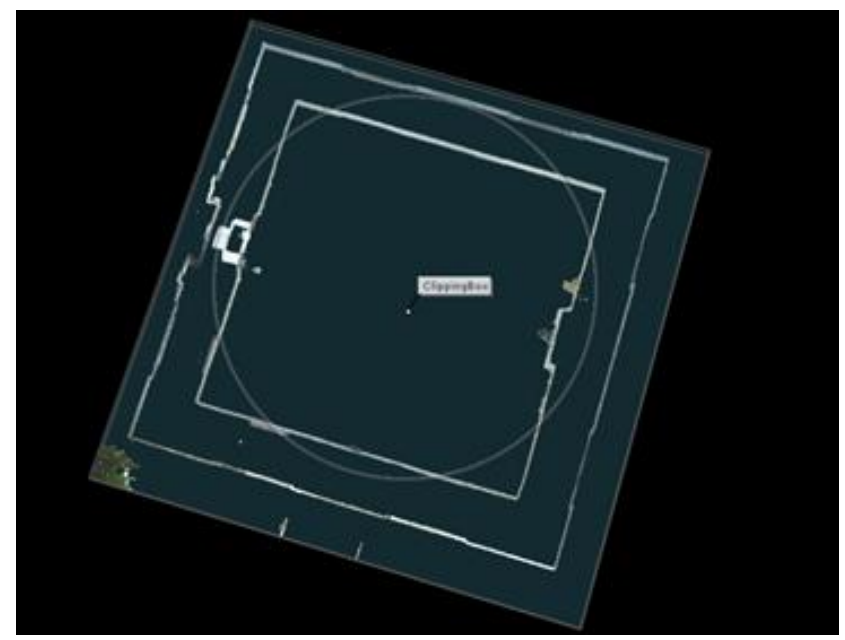

Figure 9. Ground floor plan section extraction

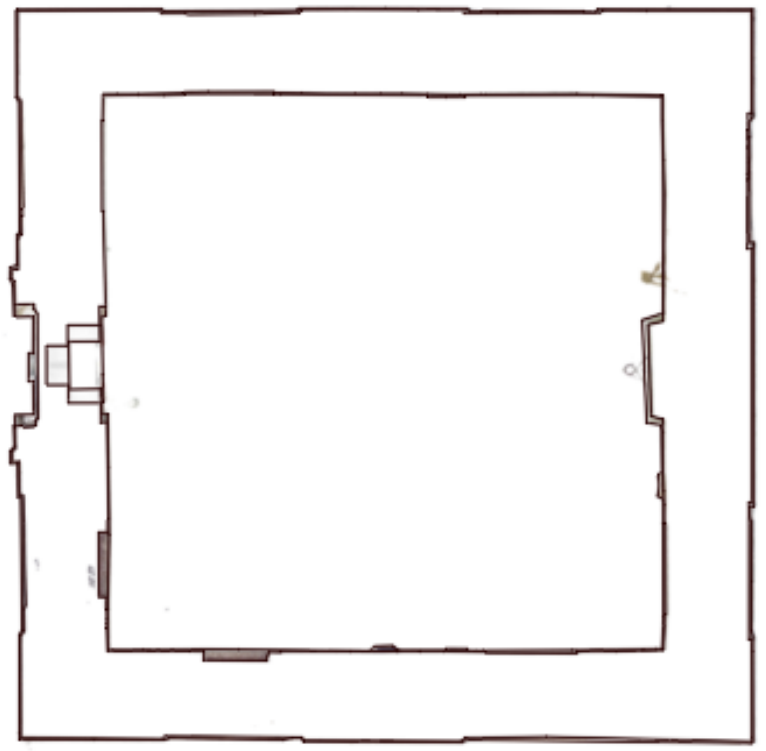

Figure 10. Manual drawing of the ground floor plan with CAD envoirement

\section{RESULTS}

Preserving cultural heritage is a requisite duty for all civilizations around the World. In order to keep the traces of civilizations alive, it is extremely necessary to pass on historical and cultural artifacts from generation to generation. The terrestrial laser scanning method has become the reason of preference for many disciplines with its potential to obtain cost effective, high-accuracy data in a short time (Okuyucu \& Çoban, 2019). Laser scanners, which ensure that the architectural documentation studies are carried out in a healthy way and in the specified standards, have become preferred by users in our country and in the world.

In this study, we present a new method for approach which reconstructs building façade models using terrestrial laser scanning data. In addition, the usability of Faro Focus 3D laser scanner and Scene software in architectural documentation studies was investigated. It was concluded that terrestrial laser scanning is a suitable method for the documentation of the heritage structure.

In the last few years, 2D representation of historical and cultural heritage and 3D modeling studies have accelerated the design processes thanks to the developing CAD software. Technical drawings, analyzes and simulations can be obtained with CAD software, which includes many modules that allow 2D and 3D work. Thanks to the point cloud function that comes with the AutoCAD software used within the scope of the study, points in the point cloud can be captured and 3D visualization can be done. It is extremely important that the software enables 3D drawing through the point cloud.

In our country, 3D modeling studies are preferred in documenting our historical and cultural heritage values. With the constantly developing CAD software facilities, the opportunity to work on 3D point cloud data will become easier and the details of complex objects will be drawn more easily. In this way, studies conducted over point clouds can provide different dimensions and new gains to heritage documentation studies. Today, this method has experienced a popular transformation, thanks to the architects who adopt the TLS technique. 


\section{ACKNOWLEDGEMENT}

We would like to thank to Azim Metin, Geomatics Engineer for providing the scanned data of the study area.

This study was presented as an oral presentation in the "The 2nd Intercontinental Geoinformation Days (IGD) 2021.

\section{REFERENCES}

Altuntaş C \& Yıldız F (2008). Yersel Lazer Tarayıcı Ölçme Prensipleri ve Nokta Bulutlarının Birleştirilmesi. Jeodezi ve Jeoinformasyon Dergisi, (98), 20-27.

Beg A (2018). 3 Boyutlu Modellemede Yersel Lazer Tarama ve İnsansız Hava Araçları Verilerinin Entegrasyonu ve Kilistra Antik Kenti Örneği. MS Thesis, Selçuk University, Konya (in Turkish).

Bonfanti C, Chiabrando F \& Rinaudo F (2013). TLS Data For 2D Representation and 3D Modelıng. Different Approaches Tested In The Case Of San Giovannı In Saluzzo (Cn) Italy. ISPRS Annals of Photogrammetry, Remote Sensing and Spatial Information Sciences. II5/W1. 37-42.10.5194/isprsannals-II-5-W1-37-2013.

González J, Riveiro-Rodríguez B, González-Aguilera D \& Rivas-Brea M T (2010). Terrestrial laser scanning intensity data applied to damage detection for historical buildings. Journal of Archaeological Science, 37(12), 3037-3047.

Gumilar I, Hawaari T, Sidiq T P \& Lukmanulhakim A (2020). As-built drawing generation of LFM building ITB using terrestrial laser scanner. IOP Conference Series: Earth and Environmental Science. 500. 012053. 10.1088/1755-1315/500/1/012053.

Hassan T A \& Fritsch D (2019). Integration of Laser Scanning and Photogrammetry in 3D/4D Cultural Heritage Preservation $-\mathrm{A}$ Review. 10.30845/ijast.v9n4p9.

Karasaka L \& Beg A A R (2021). Yersel lazer tarama yöntemi ile farklı geometrik yapıdaki özelliklerin modellenmesi, Geomatik, 6(1), 54-60, DOI: 10.29128/geomatik.664728

Kersten T P, Hinrichsen N, Lindstaedt M, Weber C, Schreyer K \& Tschirschwitz F (2014). Architectural Historical 4D Documentation of the Old-Segeberg Town House by Photogrammetry, Terrestrial Laser Scanning and Historical Analysis Digital Heritage. Progress in Cultural Heritage: Documentation, Preservation, and Protection, Springer, Heidelberg, pp. 35-47.
Kushwaha S K P, Dayal K R, Raghavendra S, Pande H, Tiwari, S, Agrawal S \& Srivastava S K (2020). 3D Digital Documentation of a Cultural Heritage Site Using Terrestrial Laser Scanner-A Case Study. In Applications of Geomatics in Civil Engineering (pp. 49-58). Springer, Singapore.

Lichti D D \& Gordon S J (2004). Error Propagation in Directly Georeferenced Terrestrial Laser Scanner Point Clouds for Cultural Heritage Recording, Proceedings of FIG Working Week, s.on CD, Athens, Greece, 22-27.

Lin Y J, Ayman H, Bullock D \& Prezzi M (2019). Application of High-Resolution Terrestrial Laser Scanning to Monitor the Performance of Mechanically Stabilized Earth Walls with Precast Concrete Panels. Journal of Performance of Constructed Facilities. 33. 04019054. 10.1061.

Moyano J, Nieto-Julián E J, Lenin L M \& Bruno S (2021) Operability of Point Cloud Data in an Architectural Heritage Information Model, International Journal of Architectural Heritage, DOI: 10.1080/15583058.2021.1900951

Okuyucu Ş \& Çoban G (2019). Afyonkarahisar Dinar Bademli Köyü Cami Röleve Projesinin Lazer Tarama Yöntemiyle Hazırlanması. The Turkish Online Journal of Design Art and Communication, 9(2),249-262.

Sevgen S (2018). Lidar Verilerinden Bina Çatı Düzlemi Otomatik Çıkarım Modeli Geliştirme. PhD Thesis, Karadeniz Technical University, Trabzon (in Turkish).

Uzun T \& Spor Y (2020). Yersel Lazer (Nokta Bulut) Tarama Yöntemi ile Rölöve- RestitüsyonRestorasyon Projesi Hazırlama Süreci ve Bir Örnek Elazı̆̆ Harput. 15.

Wojtkowska M, Kedzierski M \& Delis P (2021). Validation of terrestrial laser scanning and artificial intelligence for measuring deformations of cultural heritage structures. Measurement, 167, 108291.

Yakar M, Kuşak L \& Ünel F B (2020). Ölçme Bilgisi II. Atlas Akademi.

Faro 2020. https://www.faro.com/ Accesed Date: 03.11 .2020

Konya Metropolitan Municipality, 2021. https://www.konya.bel.tr/, Accesed Date: 01.03.2021

Culture and Tourism Ministry Official Website , 2021. https://www.ktb.gov.tr/: Accesed Date:03.02.202

Prota Altar 2020. http://www.protabilgisayar.com.tr/, Accesed Date: 13.12.2020 